\title{
Abstract
}

\section{Reported Adverse Events Following the Pfizer-BioNTech COVID-19 Vaccine in Jordan}

Areej Hamed Shoubaki, BSc, MD; Ashraf Aqel, MD; Mahmoud Yacoub, MD; Majed Asad, MD

Jordanian Ministry of Health, Amman, Jordan

Corresponding Author:

Areej Hamed Shoubaki, BSc, MD

Jordanian Ministry of Health

ALhashimi Alshamaly, Basman Erea

Hay Naifah, Next to Prince Hamazah Hospital

Amman, 11184

Jordan

Phone: 9625655166

Fax: 9625665232

Email: ajshowbaky@gmail.com

\section{Abstract}

Background: The expediency in producing and approving vaccines for the COVID-19 pandemic is unprecedented. Regrettably, this fomented public distrust and misinformation about vaccination. The Pfizer-BioNTech mRNA-based vaccine was the first to be approved for mass use after phase 3 clinical trials affirmed its safety and efficacy. Vaccine safety monitoring is ongoing.

Objective: This study aims to describe reported adverse events following immunization with the Pfizer-BioNTech vaccine among first recipients in Jordan.

Methods: A retrospective descriptive study was conducted on data extracted from the Ministry of Health's database for the National Vaccine Adverse Event Reporting System from January to May 2021. The frequency of adverse events was compared between the first and second doses and across age groups, gender, and comorbidities. The chi-square test was used to compare categorical variables.

Results: In total 1874 individuals who received both doses of the vaccine were studied. The mean age was 68 years, with a 2:1 male to female ratio and $73 \%$ with comorbidities. About two-thirds $(68 \%)$ of recipients reported side effects after the first dose, $54.3 \%$ after the second, and 53.3\% after both. Most common side effects following each and both doses were pain at the injection site $(32 \%)$, fatigue $(16 \%)$, and headache $(8 \%)$, followed by fever, myalgia, and arthralgia. Overall, reported side effects increased 1.4 times after the second dose mostly for systemic side effects. Significantly, more females reported side effects than males, while those with comorbidities reported comparatively fewer side effects (52.2\%) than the medically free (59\%). Further, 72.5\% of recipients aged 55 years or younger reported side effects compared to $50 \%$ of older recipients. No anaphylactic reactions were reported. Severe side effects were rare and self-limiting, including tachycardia $(n=4)$, shortness of breath $(n=28)$, and lower limb paresthesia $(n=6)$.

Conclusions: The Pfizer-BioNTech vaccine has proven to be safe and well tolerated among vulnerable recipients with comorbidities. Continuous adverse event surveillance and follow-up are recommended.

(iproc 2022;8(1):e36482) doi: $10.2196 / 36482$

\section{KEYWORDS}

COVID-19; Jordan; adverse events; side effects; vaccine 
Edited by Y Khader; this is a non-peer-reviewed article. Submitted 18.01.22; accepted 19.01.22; published 04.02.22.

Please cite as:

Shoubaki AH, Aqel A, Yacoub M, Asad M

Reported Adverse Events Following the Pfizer-BioNTech COVID-19 Vaccine in Jordan

iproc 2022;8(1):e36482

URL: https://www.iproc.org/2022/1/e36482

doi: $\underline{10.2196 / 36482}$

PMID:

(C)Areej Hamed Shoubaki, Ashraf Aqel, Mahmoud Yacoub, Majed Asad. Originally published in Iproceedings (https://www.iproc.org), 04.02.2022. This is an open-access article distributed under the terms of the Creative Commons Attribution License (https://creativecommons.org/licenses/by/4.0/), which permits unrestricted use, distribution, and reproduction in any medium, provided the original work, first published in Iproceedings, is properly cited. The complete bibliographic information, a link to the original publication on https://www.iproc.org/, as well as this copyright and license information must be included. 